\title{
PROTAGONISMO JUDICIAL Y REPRESENTATIVIDAD POLÍTICA ${ }^{1}$
}

A Elías Díaz, un jurista y un español heterodoxo a quien tanto le reconozco, le respeto y le estimo.

\section{Un fenómeno socio-jurídico que afecta el sistema político}

Desde hace algún tiempo se presencia un fenómeno que, con mayor o menor propiedad -tanto en lenguaje periodístico como en ciertos niveles de estudio- se denomina como protagonismo judicial. El fenómeno consiste en una aparente hiper-actividad de la acusación pública y la jurisdicción penal, llamada a intervenir en asuntos de una supuesta mayor entidad política respecto de los otros para las que regularmente aquéllas están predispuestas. En algunos casos, de manera exagerada, el fenómeno ha dado pie para que se lo denomine como «Gobierno (o República) de los jueces». Sin embargo, la denominación de protagonismo judicial que aquí se emplea convendría que no fuera confundida con la de judicial Activism, el cual es de aplicación más habitual en el ámbito de la sociología jurídica norteamericana para describir el comportamiento de los jueces, adscribiéndolo a una serie de principios o valores fundamentales en los que se encuentran un límite y una justificación para tal comportamiento (un análisis crítico sobre las diferentes posiciones que analizan el judicial Activism se encuentra en Wolfe 1991).

La cuestión parece más aguda en países pertenecientes a la cultura legal del derecho continental, sobre todo a los ubicados en la Europa del Mediterráneo norte y a algunos del área de América latina.

${ }^{1}$ Un contenido parcial de esta colaboración forma parte del trabajo publicado con el título de Protagonismo judicial y cultura de los jueces, en: «Jueces para la Democracia (Información y Debate)», n. ${ }^{\circ}$ 19-2/1933, Madrid 14-17 el cual, a su vez, constituyó una Ponencia en el Workshop: Threshold of Legality and Social Change, convocado por el International Scientific and Professional Advisory Council of the United Nations Crime Prevention and Criminal Justice Programme (ISPAC), en Valle de Aosta-Italia el 29. agosto 1993. 
Pero tal cuestión también es de una llamativa importancia en otros enmarcados en la cultura del common Law. En todo caso, el fenómeno parece estrechamente vinculado con las transformaciones que se vienen produciendo en el interior de los sistemas políticos las cuales, a su vez, se revelan como consecuencias inmediatas de cuanto está aconteciendo en la economía planetaria (cfr. Bergalli 1993). Sin embargo, lo que realmente interesa destacar aquí es que, una vez más, a través del fenómeno aludido, se demuestra con claridad algo que para una cultura crítica es por demás obvio, pero que en muchos otros ámbitos de cierta tradición jurídica existe resistencia en reconocer; esto es, la íntima relación que subyace entre el derecho y las esferas política y económica de cualquier sociedad. Cabe destacar, no obstante, que el empleo de la denominación protagonismo judicial conviene reservarla a un tipo de comportamiento de los jueces quienes, sin apartarse del marco de un Estado de derecho ha asumido una resonancia particular a causa de ciertas falencias que se producen en el entero sistema político dentro del cual los magistrados deben actuar.

Mas, cuanto acaba de decirse no es sólo materia de discusión académica; también puede verificarse en el terreno de la praxis jurídica. Ejemplos de ello se cuentan hoy por millares y, para no ir más atrás en la historia de la cultura jurídica universal, pueden destacarse los casos italiano y español más recientes. Así puede comprobarse hasta qué punto, particularmente ciertas áreas de la legislación penal de esos países han sido últimamente puestas en cuestión, se las ha pretendido reformar o han sido reformadas bajo la fuerte presión que ejercen los fenómenos de criminalidad económica organizada, deslegitimación de buena parte de la clase política y de algunos sectores tanto del empresariado como de las más elevada burocracia en ambos países. Estos últimos, implicados en múltiples investigaciones judiciales por situaciones de corrupción y financiamiento ilegal de partidos políticos, cuando no de enriquecimiento ilícito.

\section{Lectores de la legalidad o intérpretes críticos de ella}

Con lo dicho hasta ahora parece que se han suministrado algunos elementos para reflexionar acerca de un aspecto central que hoy se destaca en lo que se puede comprender como cultura jurídica habida cuenta que, dentro de las múltiples concepciones que de ésta se pueden dar, una amplia ha de encerrar algo más de los aportes que a ella entregan los juristas prácticos, con su trabajo profesional y los académicos, con sus estudios doctrinales. En efecto, la contribución 
que a ella hacen los jueces -tanto cuando producen derecho (mediante sus decisiones jurisdiccionales), como cuando se manifiestan sobre la realidad circundante, pero como miembros de la corporación judicial- es también una manifestación de la cultura jurídica. Así lo entiende no únicamente el asociacionismo judicial más avanzado en Europa continental (cfr., por todos, los más recientes aportes de Magistratura Democrática 1994), sino también aquella sociología jurídica originada en las distintas versiones del realismo norteamericano (cfr. Cotterell 1984: 186 y ss.). Tampoco el tema ha sido extraño al ámbito de la teoría del derecho continental europea y así se ha revelado cuando ella se ha planteado la concepción de la actividad de los juristas como fuente del derecho y la existencia de un derecho judicial o jurisprudencial que según las tradiciones de pensamiento jurídico se enuncia como Juristenrecht o Judges make Law (cfr. Baratta 1990), aunque sobre este punto se volverá más adelante.

Ahora bien, la cultura jurídica, genéricamente así presentada, no sirve sino para describir las actitudes y las definiciones que frente al y del derecho pueden dar quienes, de una manera u otra, participan íntimamente en el momento de producción normativa. En cambio, otro concepto que aquí me interesa destacar es el que se conoce como cultura de la legalidad, puesto que es en su ámbito donde los jueces de las sociedades democráticas se confrontan hoy abiertamente con el mayor desafío al que tiene que responder la forma-Estado de derecho.

Esta cultura de la legalidad nace de la distinción weberiana entre legalidad y legitimación racional del poder, sobre lo cual parece hoy día prudente hacer una recapitulación, por lo menos por dos tipos de razones. El primero de estos tipos, concierne a la naturaleza y nombre del Estado legal, esto es, al tipo de organización política que está fundada sobre la legalidad. El segundo, por otra parte, concierne a la interpretación de formas de conducta social que evitan, eluden o engañan a la legalidad en tanto que su definición formal no queda afectada (v. Resta 1993).

Por todo esto, quizá sea oportuno comenzar a pensar si el protagonismo judicial del cual me ocupo aquí forma parte o de verdad representa un papel importante en esa tentativa de recomposición de la identificación entre el comportamiento social y la normatividad -entendida ésta como la expresa el derecho positivo (racionalidad formal)- la cual, al parecer, hoy está en crisis y expandida en muchas zonas del mundo occidental.

El problema que aquí se pretende proponer es, entonces, el de saber hasta qué punto la jurisdicción puede intervenir, provocando una disminución en la elección de conductas ilegales, al demostrar 
que la racionalidad del egoísmo (o la lógica del free riding, de la que habla Resta (en op. cit.) no puede seguir orientando el comportamiento social. Un motivo para que esto no haya sido resuelto hasta hace poco en la cultura jurídica tradicional radica en el apego que ella ha demostrado a esa racionalidad formal.

Pero, la respuesta al problema que se propone no se puede satisfacer si no se analizan los motivos del propio comportamiento de los jueces. Una actitud firme, como la asumida por un relevante sector de la clase judicial italiana, y algunos de la similar española, frente a los fenómenos de criminalidad organizada, corrupción política y complicidad de una vasta franja del empresariado (también esto está acaeciendo, aunque en otra medida y condiciones del sistema político, en los ámbitos alemán y francés), ha sido sólo posible por la revalorización del papel del juez que ha tenido lugar en la cultura jurídica como intérprete de la legalidad. Puede decirse, entonces, que efectivamente la respuesta que se pretende debe buscarse en el plano de la cultura, aunque en un sector específico de ella como lo es la cultura jurídica y, en particular, la cultura de los jueces.

El tema es central en el debate socio-jurídico contemporáneo pues estas dos últimas culturas se han alimentado tradicionalmente de unas concepciones sobre el derecho, sus procesos de creación, interpretación y aplicación, de una forma tal que lo han hecho entender de manera instrumental e idónea para el desarrollo del único modelo social que parece extenderse por todo el planeta. Empero, este modelo está siendo duramente cuestionado por estar demostrando ser una fuente de desequilibrios y de injusticias, de crecientes separaciones entre el Norte y el Sur del mundo, de miseria y de hambre para inmensas masas de hombres y de pueblos, de peligros de guerra y de catástrofes ecológicas.

Como se sabe, entonces, la deslegitimación del modelo social ha acarreado la del sistema político y así, la de los aparatos de Estado. El punto más agudo de esta crisis se verifica en la caída de representación que afecta a los actores de la mediación entre el nivel de la sociedad civil y el del Estado. La jurisdicción y los jueces, según la tradición de la cultura política y jurídica de derecho continental, no tienen asignados tareas de representación pero son severamente cuestionados cuando en cierta manera, requeridos por una función de representación suplente, toman decisiones en asuntos de entidad más política que en otros. Es en este punto, en consecuencia, en el cual convergen la crítica a la cultura jurídica con la crítica al papel funcional que los jueces cumplen si ellos mantienen y prolongan el paradigma de la interpretación del derecho, asentado en una racionalidad formal, al constituirse en meros lectores de la legalidad. 


\section{La ambigüedad del derecho moderno y la interpretación judicial}

Es perfectamente correcta la denuncia de la falsa igualdad de las personas ante el derecho, en especial ante el derecho penal, y la cobertura que ella ofrece a las desigualdades reales, como al papel de dominadores y explotadores que cumplen los sujetos socialmente más fuertes. De la misma manera lo es la acusación de legitimación ideológica de las situaciones existentes llevada a cabo hasta ahora por el falso universalismo de los «valores» (bienes) jurídicos que protegería el derecho penal.

La alta complejidad y el elevado nivel de conflictividad alcanzado en el campo de las relaciones sociales contribuyen sensiblemente a que el derecho no pueda alcanzar el grado de racionalidad substancial que le permitiría mediar entre partes desiguales. De este modo, se marca con evidencia el carácter ambiguo en el que se mueve el derecho y toda la cultura jurídica tradicional. Aún más, esta ambigüedad es, desde siempre, la connotación no sólo del derecho sino de toda la cultura occidental de la Modernidad. Esta última ha construido una dimensión axiológica universal que se ha prestado a ser empleada y aplicada a objetivos parciales e instrumental izada como máscara de las finalidades de conquista, de atropello y de explotación. Todo esto lo ha enseñado Marx y sería absurdo olvidarlo. La conciencia expresada por los «valores» occidentales -respeto por la vida humana, propiedad, honor, justicia, derecho, derechos del hombre y del ciudadano-, transferidos al derecho penal como bienes jurídicos dignos de protección, han podido transformarse en falsa conciencia. Mas, sin embargo, ésta es la ambigüedad que ha sido desde siempre propia del derecho, por lo cual ella se plantea como un terreno de lucha no sólo en lo que respecta a su producción, sino también en lo que atañe a los usos y a las instrumentalizaciones que con él pueden ser realizadas las que, por cierto, necesitan ser contrastadas.

No obstante, de vez en vez, esta ambigüedad del derecho penal ha podido ser aplicada con sentido progresivo, dependiendo ello no sólo de las relaciones de fuerza sino también del rol -más avanzado que subalterno, de transformación antes que de conservacióndesempeñado por la filosofía política y por la cultura jurídica. Dentro de esta última, la cultura crítica de los jueces cumple un papel descollante pues su tarea es hoy, sin duda, la de disolver semejante ambigüedad, asumiendo el derecho «en serio» (Dworkin 1977), aún cuando se tenga certidumbre que ella no será jamás totalmente disuelta y que la falsa conciencia continuará siempre acompañando y minando la conciencia moral e intelectual de los juristas. 
¿Cómo pueden la jurisdicción y los jueces colaborar en la disolución de tal ambigüedad? La tarea es quizá hoy más sencilla que en el pasado. En efecto, si bien es apropiado seguir denunciando la dicotomía entre racionalidad formal y racionalidad substancial -de la cual ha sido víctima hasta ahora la cultura jurídico-penal y en general todo el sistema penal-, sin embargo, tal dicotomía puede ser superada por el paradigma de la interpretación constitucional (cfr. Zagrebelsky 1992, esp. 199-203) en la cual ha tomado lugar la racionalidad substancial, bajo la forma de los derechos fundamentales y las garantías individuales. De esta manera, los conflictos entre moral y derecho, entre valores y hecho, entre normatividad axiológica y eficacia concreta, entre idealismo y realismo; finalmente, entre racionalidad substancial y racionalidad formal se convierten en antinomias jurídicas entre normas positivas e interpretación de ellas por los jueces, en las cuales resalta el proceso de formación en el que tuvo origen el Estado democrático de derecho (Ferrajoli 1992).

En virtud de esa penetración de la racionalidad substancial, bajo la forma de la interpretación constitucional del derecho penal positivo, la ambigüedad que caracteriza a éste cambia de naturaleza. Es verdad que existe un fuerte temor por una temida «explosión» subjetivista de la interpretación, pero ese temor está alentado por la parcialidad que representa la comunidad de los juristas adheridos al simple formalismo. Cuando los principios constitucionales dejan de ser externos al ordenamiento jurídico y se convierten en una fuente de legitimación de todo el sistema penal, la hermenéutica jurídica tradicional sufre un rudo golpe. De tal forma, asimismo, pierde veracidad la tesis kelseniana según la cual la validez de las normas es un hecho puramente formal que depende sólo del modo de la producción normativa. La validez, en efecto, se convierte en un hecho también substancial el cual, al mismo tiempo, depende de las decisiones de la jurisdicción que resultan inválidas cuando se revelan en contraste con los valores constitucionales, incorporados al sistema penal por la interpretación jurisprudencial.

En ese sentido, la idea de racionalidad sobre la que se ha sostenido la Modernidad $\mathrm{y}$, en consecuencia, el derecho moderno, observado éste a la luz de una cultura de la legalidad, bien pueden estar agotados (así lo está afirmando un buen número de Autores que, en el mundo anglo-norteamericano se identifican con una cultura jurídica crítica -los Critical Legal Studies o los análisis sobre Law and Society- y en el ámbito europeo continental descienden directamente de la tradición gramsciano-frankfurtiana) como lo están las grandes narraciones que caracterizaron a la cultura moderna. Por esto se explican las búsquedas de arraigo a un nuevo concepto de racionalidad y, en consecuencia, la amplia aceptación que comenzaron a tener 
ciertos modelos interpretativos del sistema social. Sin embargo, algunos de ellos, en una visión sistémica muy particular, entienden la legitimación del subsistema jurídico pero desplazando la consideración del hombre; éste es el reproche que se le formula a Luhmann (cfr. por ej. Izuzquiza 1990).

De este modo, una forma de proponer la legitimidad de la legalidad en esta perspectiva no es más la de describirla como la verdad reconocida de las demandas de validez, sino como la de alcanzar la integración de dos procesos de aprendizaje diferentes, a saber: a) el de quien toma las decisiones (el juez) acerca de cuáles son las estructuras cognitivas de esperanzas de comportamiento social que el derecho positivo acoge y sobre las que puede decidir y b) el del afectado y otros terceros que aceptan la decisión (del juez) porque con ella se legitiman sus esperanzas respecto del comportamiento de terceros (Luhmann 1972- II: 261).

Mas, esta propuesta de Luhmann se enmarca en la más general que le permite entender el sistema social como un «sistema de acciones, interacciones, roles y estructuras selectivas de sentido» y al hombre como «ambiente problemático del sistema mismo» (1971: 26 y ss.), la cual, sin embargo, adolece de una obvia inconsistencia lógica. En efecto, si por un lado se niega que el hombre haga parte del sistema social, por el otro, sin ninguna preocupación, se considera que las relaciones sociales del hombre, vale decir sus acciones, interacciones, roles y estructuras selectivas de sentido son, en cambio, fundamentales partes constitutivas del mismo sistema social. Esto hace muy difícil entender cómo el hombre, de un golpe convertido en ambiente o entorno (Umwelt), sea capaz todavía de desempeñar funciones de ambiente problemático del sistema. Sin embargo, detrás de esta inconsistencia se esconde una teoría sobre la reducción de la complejidad en la cual los procesos jurídicos juegan un papel descollante, pero con la que se evitan las interferencias de los individuos en los procesos decisionales. Desde este punto de vista, entonces parecería que fuese ideal tener al hombre fuera y no dentro del sistema social (Maldonado, 1992: 162) lo cual, por cierto, contradice una de las tradiciones más fuertes de la teoría social, pues sea ésta del signo que fuere siempre ha privilegiado precisamente al hombre como centro del sistema social de que se trate.

\section{Una concepción post-moderna del derecho y la cultura de los jueces}

Lo expuesto hasta ahora ha pretendido traducir una cierta manera de reconstruir los fundamentos racionales sobre los que se ha basado 
la cultura jurídica moderna. Pero, tal como ha sucedido en otros ámbitos de la cultura occidental, particularmente artísticos, ¿puede hablarse también en el terreno jurídico -como algunos autores lo hacen (cfr. por todos, De Sousa Santos 1992)- de una quiebra de la racionalidad que el discurso post-modernista ha introducido en el debate cultural?

Si este discurso post-modernista se ha gestado evidentemente en torno a la credibilidad de la Modernidad en sí misma, como una auto-denominación de la civilización occidental, bien industrial o post-industrial, bien capitalista o post-capitalista, ello implica que los atributos auto-adscriptos, contenidos en la idea de Modernidad, ya no se sostienen hoy día y quizá tampoco se sostenían ayer. El debate post-modernista se concentra alrededor de la auto-conciencia de la sociedad occidental y de los fundamentos (o la ausencia de ellos) de tal conciencia.

No muchos estudios han sido realizados acerca de una concepción post-moderna del derecho. En todo caso, en algunos destaca como rasgo central el carácter declinante del derecho como medio de integración social lo cual se generaría por variados motivos, según los autores, pero que en general se produciría por una creciente intervención del Estado. Esto es lo que Habermas denomina como crisis de racionalidad (cfr. 1979: 87 y ss.), la cual emerge porque el Estado toma prestado para satisfacer sus funciones; por consiguiente, de esta manera se gesta una gravosa inflación y una crisis financiera. Así nace la crisis de racionalidad porque los problemas están arraigados en la incapacidad del Estado para reconciliar los diferentes y conflictivos intereses del capital privado. La irracionalidad básica es la que los marxistas denominan usualmente como la «anarquía del mercado»; o sea, la idea de que una sociedad ordenada puede ser construida fuera de los intereses privados en conflicto.

En el nivel de la integración social, la crisis de racionalidad aparece como una crisis de legitimación (Habermas op. cit.: 96 y ss.). En efecto, si el Estado no puede encontrar las estrategias correctas para reconciliar los intereses en conflicto que trata de regular, entonces pierde legitimidad a los ojos de los ciudadanos; falla en su tarea y la justificación de su existencia se hace confusa.

Pero, si la crisis de racionalidad puede ser reconducida en el subsistema político, entonces la escena cambia hacia el subsistema sociocultural y puede surgir el tercer tipo de crisis: la crisis de motivación (Habermas op. cit.: 106 y ss.). Por lo tanto, si la crisis económica es una crisis de integración del sistema, y la crisis de racionalidad es una crisis del sistema y de integración social, entonces la crisis de motivación es únicamente una crisis de integración social. 
Ahora bien, ¿cómo incide esta perspectiva -que supone el resumen de variados enfoques sobre las diferentes crisis que atraviesan en la actualidad al Estado democráticosobre la racionalidad del discurso jurídico? Evidentemente, con una caída de legitimación de la legalidad y del sistema jurídico.

Pero, dicha perspectiva se asienta en una única dimensión de la comprensión del derecho como derecho estatal, lo cual constituye una de las características básicas de la cultura jurídica moderna. Éste es el punto de partida de la construcción de un «nuevo sentido común jurídico» (de Sousa Santos 1992 op. cit.: 23) pues, como resultado de la llamada «re-contextualización» del derecho, emerge el reconocimiento de espacios y tiempos como contextos de producción jurídica. Estos contextos serían: el doméstico (relaciones sociales entre los miembros de la familia), el de producción (relaciones en el ámbito del o en el trabajo), el de ciudadanía (relaciones sociales en la esfera pública, entre los ciudadanos y el Estado) y el mundial (relaciones económicas internacionales y entre Estados nacionales).

En este cuadro estaría el germen para el reconocimiento del pluralismo jurídico, el cual se revela como concepto clave en una visión post-moderna del derecho. Pero, aquí no se habla del pluralismo legal de la tradicional antropología jurídica, en la cual los diferentes órdenes legales son concebidos como entidades separadas que coexisten en el mismo espacio político. Por el contrario, se alude a la concepción de diferentes espacios legales superimpuestos, interpenetrados, que de forma mezclada actúan en las mentes como sobre las acciones humanas, en ocasiones a saltos cualitativos o provocando tanto crisis en las trayectorias vitales cuanto sobre la obscura rutina de las vidas cotidianas. Se vive, entonces, un tiempo de porosidad legal o de legalidad porosa por la coexistencia de múltiples redes de órdenes legales, los cuales impulsan a las personas a constantes transiciones y traspasos de uno a otro. Por tanto, la vida legal de la post-Modernidad está constituida por una intersección de diferentes órdenes legales; esto es, por la interlegalidad que así resulta ser el complemento fenomenológico del pluralismo legal y, en consecuencia, el segundo concepto clave de una concepción post-moderna del derecho (de Sousa Santos 1987: 298).

Mas, la interlegalidad constituye un proceso de elevado dinamismo a causa de que sus diferentes espacios legales no operan de modo sincrónico, lo cual genera unas mezclas inestables de códigos legales, en sentido semiótico. De tal manera, la ampliación del espacio legal, hacia una escala mundial o planetaria, puede provocar la aparición de nuevos particularismos y nuevos personalismos, lo cual evoca el renacimiento de privilegios o corporativismos de las diferentes 
profesiones jurídicas. Evidentemente, este aspecto constituye un cierto aliento al protagonismo judicial aunque este mismo ya no sea el propio que puede emerger en el marco de consideración de un mundo legal policéntrico, en el cual el único referente es el derecho del Estado, lo que sigue siendo un factor político decisivo.

De todas maneras, los ciudadanos están más cerca de los órdenes legales que afectan a sus realidades cotidianas y se sienten alejados de los que no las rozan, por lo cual y por razón de las formas de socialización y aculturación que imperan en la sociedad industrial, la legalidad a la cual se adscribe el comportamiento social es la dictada por el orden del Estado nacional. No obstante, puede decirse que la vida en la sociedad post-industrial está de verdad regida por órdenes legales supra (ONU, Comunidad Europea, Acuerdos de Schengen, Grupo de Trevi) e infra-estatales (ámbitos doméstico y de producción) que poco a poco han minado el concepto de derecho estatal e, incluso, el principio de la soberanía. Esto es lo que ayuda a configurar un nuevo sentido legal común como el tercer concepto clave en la concepción post-moderna del derecho la cual, en esencia, se presenta como un sentido común pluralista.

No obstante, una semejante concepción está todavía en fase inicial de elaboración. Para que la cultura jurídica que depende férreamente del derecho estatal acepte ese sentido común pluralista, deberán todavía vencerse muchos de los fetichismos que la alimentan y habrá de aceptarse que la cultura de la legalidad no podrá entenderse más como la conformidad del comportamiento social prescripto por el derecho. En efecto, el pluralismo jurídico supone que las prácticas jurídicas incluyen siempre algunos momentos de ilegalidades, pues la porosidad de los diferentes órdenes legales que atraviesan la realidad de la sociedad post-moderna obligan a constantes transiciones y transgresiones.

Estas últimas reflexiones -que modestamente pretenden introducirse en el debateno sólo traducen un desafío para la cultura de los jueces quienes, de aceptar las propuestas de la concepción post-moderna del derecho, asumirían otro tipo de protagonismo, cuestionador de valores y bienes jurídicos tradicionales. Constituyen también, sin duda, un esbozo de poner a prueba ciertos principios que alientan particularmente la ética profesional los jueces penales, en cuanto éstos deben someter sus convicciones morales por los vínculos de estrecha legalidad a aplicar o no aplicar exactamente las leyes. En este caso, una nueva hermenéutica jurídica, orientada por los parámetros constitucionales, debe guiar a los jueces a valorar su obligación jurídica de someterse a la ley, dentro de espacios inevitables de autonomía moral y de responsabilidad política (Ferrajoli 1989: 969). 


\section{Las caídas de representatividad política y la forma-Estado: el papel de los jueces. Manifestaciones en el centro del sistema europeo}

He aludido antes al papel que los jueces y la jurisdicción parecen haber asumido en ciertos países, en los cuales la crisis del sistema político afecta el nivel de relaciones entre la sociedad civil y el Estado. La situación se hace a cada momento más aguda: Tangentopoli en Italia ha generado un verdadero terremoto político, hasta el punto de haber provocado el llamado fin de la prima Repubblica. Está por verse qué ocurrirá finalmente en Francia con la continuación de la investigación judicial conocida con el calificativo periodístico de Pieds propes y en España, en el último año, sus ciudadanos no han dejado de salir del asombro cotidiano que provocaron las revelaciones verdaderamente sorprendentes acerca de la corrupción en la que han estado envueltos los más altos cargos de la banca estatal (caso Rubio), de la seguridad del Estado (caso Roldán) o de la cúspide del partido en el gobierno (caso Filesa). Sin embargo, el caso más alarmante, por las revelaciones que está aportando, las implicaciones que se manifiestan, y las imprevisibles consecuencias que puede generar, es la ya famosa investigación sobre los GAL y la utilización de fondos reservados para las actividades criminales de estos grupos. Todos estos casos han dado ocasión a un cierto protagonismo judicial de enormes repercusiones en el plano de la vida política española. Semejante corrupción, por otra parte, ha provocado la debilidad del partido en el Gobierno (PSOE) y lo ha obligado a buscar apoyos en fuerzas políticas nacionalistas (CiU, de Catalunya, y PNV, del País Vasco) para no perder la mayoría parlamentaria con la cual pueda mantener la gobernabilidad.

El cuadro sintéticamente descripto no sólo ha hecho variar las líneas estratégicas de las políticas estatales en esos tres países europeos; también ha generado un clima de inestabilidad generalizada frente al cual han surgido cambios radicales en la composición de los propios gobiernos. El caso italiano resulta paradigmático en cuanto que las elecciones de marzo de 1994 significaron un triunfo de las posiciones de la derecha, integrada en tres fracciones que reflejan intereses socioeconómicos y políticos, e incluso modelos de Estado, absolutamente contrastantes entre sí, cuales son: los más heterogéneos de Forza Italia, liderados por el magnate Berlusconi, que procuran la limitación de la intervención estatal en todos los campos; los regionalistas de la Lega Nord, que auspician un proyecto federalista, tachado incluso de secesionista, a través del cual se intenta el desmembramiento económico y social del país; y, los fascistas del Movimento Sociale Italiano que no sólo plantean el 
fortalecimiento del Estado unitario y centralista, sino que suponen la amenaza más aciaga para el futuro democrático de Italia y de toda Europa, en cuanto son los herederos de las ideas de Benito Mussolini.

En los momentos de preparar esta contribución son las situaciones políticas en Francia y en España, las que evolucionan en un sentido más previsible. No obstante, sin haberse concretado un vuelco tan radical como en Italia, no pueden dejar de preverse transformaciones profundas que pueden constituir tanto el cambio de las alianzas sobre las cuales se sostienen sus gobiernos, cuanto la posible entrada en estos de fuerzas de las actuales oposiciones parlamentarias.

Si bien el panorama italiano se manifiesta de manera única, tampoco es muy alentador el de buena parte de Europa continental, sin por supuesto entrar en la consideración de los imprevisibles movimientos que se están produciendo en los Balcanes y en los Urales. En estas áreas las situaciones asumen en algunos casos tintes dramáticos para la frágil convivencia o incluso para la subsistencia aunque no hayan existido, hasta ahora, realizaciones del Estado democrático de derecho como en el occidente europeo.

Mientras tanto, lo que ha sido innegable en estos últimos años de gran parte de Europa continental es un activismo particular de los jueces. Allí donde los derechos civiles han sido atacados, donde las iniciativas de los ciudadanos han necesitado apoyo, donde la moralidad pública ha tenido que ser tutelada, donde nuevos derechos han debido ser promovidos, donde el terrorismo o la criminalidad organizada se han convertido en grandes fenómenos sociales, pues allí se han reproducido las imágenes que han acompañado a los jueces. Estos no son únicamente alternativas italianas (no obstante que haya sido en Italia donde la conciencia democrática de la clase judicial ha sido manifiesta) y no pueden, de modo alguno, ser analizados desde la perspectiva de la «politización de la justicia», tal como en algunas ocasiones se ha reprochado desde la clase política. Sin negar la existencia de algunos casos en los cuales jueces individuales o tribunales aislados se han hecho protagonistas en situaciones en que de manera evidente han existido vinculaciones entre estructuras judiciales y poder político, en otra mayoría de casos la tendencia general ha constituido la dilatación del papel de la jurisdicción en el conjunto del sistema político.

5. 1. La creatividad del juez y la politización de la jurisdicción. No obstante, la denominada «politización de la actividad jurisdiccional» puede y también debe ser analizada con otro enfoque. En efecto, si la resolución de una controversia se realiza con la mediación de un juez, no debe sorprender que ella adquiera un cierto relieve 
político puesto que de este modo se asiste, dicho de una forma bastante banal, a una manera de expresión de la función política fundamental de asignación de valores en un caso concreto.

El hecho de que el juez deba actuar mediante la aplicación de normas jurídicas o de precedentes que revisten carácter normativo, supone un aspecto que refuerza la capacidad de solución de conflictos que posee la jurisdicción pero, asimismo, acentúa inmediatamente su politicismo al hacer partícipe al juez de la función de aplicación de las normas. Si, en cambio, la tarea del juez estuviese limitada a aplicar de modo pasivo al caso concreto las reglas provistas por el sistema normativo de la sociedad en que actúa, una tal constatación no merecería, por cierto, una gran atención. Pero, el caso es que así se abre un problema de mucho mayor relieve, esto es saber si y en cuál medida semejante actividad es conducida de forma autónoma respecto al sistema normativo. En otras palabras, de lo que se está hablando aquí es del problema de la creatividad jurisprudencial.

La aceptación de que un cierto grado de creatividad es connatural al proceso de interpretación de las normas abre el camino para el reconocimiento de una determinada discrecionalidad en la actividad jurisdiccional. Ésta es una cuestión cuyas raíces deben ir a buscarse en el estudio de la actividad de los juristas como intérpretes y aplicadores del derecho, terreno sobre el cual se han escrito agudísimos análisis en la búsqueda de una relación entre la ley y su aplicación judicial la cual, como se sabe, se ha movido tradicionalmente entre dos extremos: el positivismo jurídico, en sus diversas variantes, y su opuesto que puede denominarse como liberalismo jurídico, el cual también tiene diferentes expresiones. Mas, las relaciones entre ley y derecho han tenido distintas orientaciones históricas en Europa continental cuyas repercusiones han sido evidentes en la conceptualización del Estado de derecho, según sea una más vinculada a la idea francesa de la división de poderes u otra de carácter conservador y en cierto sentido autoritaria de la escuela histórica alemana (cfr. Baratta, op. cit.: 190-206). De todas las maneras, en cualquiera de esas orientaciones, el concepto de legalidad supone que la legitimación de la intervención del juez debe provenir de su configuración como profesional y no como político. Un concepto semejante implicaba, aunque con variantes muy peculiares en la tradición germana de un derecho judicial (cfr. Baratta op. cit.: 198-201), la exclusión de dicha intervención del área del decisionismo. El juez, por lo tanto, actúa como un técnico dentro de espacios de acción determinados por reglas técnicas aún cuando no de una manera absoluta. De aquí proviene que el respeto de la legalidad se producía sobre la base de la capacidad profesional del juez para salvaguardar la certeza del derecho. 
Pero, aun cuando discrecionalidad no significa necesariamente arbitrio, la verdad es que el juez se enfrenta casi siempre con situaciones en las cuales debe realizar elecciones entre interpretaciones alternativas diferentes. De tal manera, si el juez puede elegir entre alternativas, su decisión puede convertirse en una fuente de incertidumbre para quien espera tal decisión. En consecuencia, actuando de este modo el juez adquiere poder, que es poder político vista su posición y los efectos de sus decisiones, las cuales asumen una especial relevancia en el caso de jueces que integran tribunales colegiados, tales como las Cortes Supremas o Tribunales Superiores por la influencia que ejercitan sobre otros inferiores al elaborar verdaderas y propias normas de carácter general (cfr. Bergalli 1984: 61).

Si la creatividad jurisdiccional es entonces un hecho ampliamente reconocido, esto no significa que ella pueda expresarse en total libertad (cfr. Cappelletti 1984: 13). Aún cuando sea difícil llegar a determinar el grado de creatividad, siendo tantos los factores en juego, lo que basta aquí es señalar la presencia del fenómeno y de su difícil reversibilidad, por lo menos en los sistemas democráticos contemporáneos. En efecto, como ha sido destacado, (cfr. Cappelletti op. loc. cit.) este fenómeno no se conecta únicamente con una serie de movimiento culturales -muchos de los cuales pueden incluirse en la llamada «revolución contra el formalismo»- que han erosionado con fuerza la veracidad de la tradicional concepción del papel del juez como el de aquél que se limita a aplicar la ley al caso concreto, sino que encuentra su raíz en un número de factores mucho más complejos.

Antes de nada, los márgenes de creatividad de la actividad del juez han sido ampliados por los desarrollos del constitucionalismo social el cual, en la segunda mitad del presente siglo, después de la Segunda Guerra Mundial, ha difundido en muchos países europeos la justicia constitucional de las libertades y ha otorgado mayor participación a las declaraciones -nacionales e internacionales- de los derechos fundamentales del hombre. Pero, también en los países como Alemania e Italia (al que debe agregarse ahora España), en los cuales el control de constitucionalidad de las leyes ha sido confiado a tribunales diferentes de los ordinarios, la novedad ha terminado por influenciar todo el sistema judicial, modificando así en un sentido más activo la concepción prevaleciente sobre el papel del juez.

Lo que puede comprenderse como la gran transformación del papel de la magistratura en las sociedades contemporáneas está de cualquier modo relacionada, sobre todo, con algunas modificaciones que se han manifestado en el marco de realización del Welfare State y con el expansivo gigantismo de las grandes organizaciones económicas y políticas. 
En efecto, muchas han sido las causas de semejante transformación. Otros instrumentos de regulación social entraron en crisis y la jurisdicción, sobre todo en sociedades fragmentadas, ha surgido como el único elemento de referencia común dotado de una legitimación institucional en lo que se refiere a la resolución de conflictos. Además, con la creciente complejidad social ha aumentado el número de los derechos y, con ello, también se han dificultado sus realizaciones espontáneas o a través de los tradicionales instrumentos administrativos. Es de este modo, entonces, que surgen nuevos conflictos e irresistiblemente tienden a ser «jurisdiccionalizados». De esta manera es que la jurisdicción deviene más bien, en primer lugar, un momento de visibilidad para los nuevos conflictos entre ciudadanos, Estado y grandes organizaciones, todo lo cual ha reforzado entre los primeros la necesidad de protección respecto a los aparatos administrativos y a los poderosos intereses económicos que cada vez más interfieren en la vida de los individuos. Precisamente por sus características procedimentales, lo que obliga a dar una respuesta a las demandas del ciudadano, el sistema judicial se ha visto requerido para intervenir en situaciones concretas que afectan intereses singulares en relación a esas grandes organizaciones públicas y privadas. De este modo, la exigencia de controlar las acciones de estas organizaciones ha sido satisfecha en la mayor parte de los países democráticos mediante el papel más activo de los órganos judiciales tradicionales.

Sin embargo, dado que la creatividad jurisdiccional se manifiesta sobre todo como un aporte autónomo del juez al proceso de interpretación de las normas, su percepción será favorecida también por la diferenciación, al menos parcial, de las orientaciones interpretativas del juez respecto a las prevalecientes en la comunidad política y, en particular, en las otras estructuras de autoridad de la sociedad, lo cual tenderá a asumir un relieve especial en aquellas culturas políticas caracterizadas por su baja homogeneidad. Esta opinión vendría a indicar que, cuanto más elevada es la heterogeneidad social y política, mayor riqueza adquiriría la interpretación jurisprudencial.

Muchas son las posiciones que han intentado conciliar la facultad creativa de los jueces con su responsabilidad democrática. La que lo ha hecho del modo más simple acepta la crítica de la tradicional teoría de la interpretación y, por lo tanto, el presupuesto de la creatividad jurisdiccional (cfr. Friedman 1961). En otras palabras, se reconoce que el juez, en el curso de su actividad jurisdiccional, no puede dejar de crear derecho -por lo tanto, de hacer política- pero se resuelve el problema sosteniendo que tal creatividad se desenvuelve o, más bien, es desenvuelta en forma de no entrar en conflicto con las orientaciones de las instituciones político- representativas. Se trata, 
en consecuencia, de una creatividad intersticial que tiene lugar dentro de los márgenes dejados libres más o menos voluntariamente por otras instituciones. De tal modo, el politicismo del papel de los jueces, aunque presente, es siempre un politicismo más bien delegado por quien representa la comunidad política. El juez rellenaría con sus valoraciones los espacios dejados abiertos por el legislador, por ejemplo con el uso de cláusulas generales, o si se aventura en sectores nuevos, no cubiertos por la ley, pero únicamente hasta cuando las instituciones político-representativas no reaccionen. Con esta visión, el juez resuelve controversias sobre la base de normas que poseen el consenso implícito o explícito de los órganos que representan la comunidad; en este caso, su politicismo no puede constituir un problema desde el punto de vista democrático. Esta es una posición que resulta frecuente en los países de Common Law. Según Bell (cfr. 1983:244-246), ésta es una fiel descripción de cómo los jueces británicos se comportan efectivamente. También respecto de los Estados Unidos hay quien habló de un papel de este tipo. Por ejemplo, según Dahl (cfr. 1957), la Corte Suprema federal, aun ejercitando a menudo una notable dosis de creatividad interpretativa, no había entrado jamás seriamente en conflicto con las fuerzas políticas dominantes pues ella efectivamente hace parte, por regla, de la coalición dominante en el nivel nacional.

Más allá de su cuidado en describir los reales comportamientos de los jueces, esta definición del papel que estos cumplen no carece de un cierto realismo dado que reconoce explícitamente el fenómeno ya afirmado en casi todos los países de régimen democrático; es decir, la acentuada creatividad jurisdiccional. Sin embargo, esta posición también sostiene que los jueces en realidad no deciden -o por lo menos, no deben decidir- en contraste con las orientaciones prevalecientes en el sistema político, de forma tal que, actuando así, se resuelve la tensión entre jurisdicción y sistema político democrático.

No obstante, no todas las posiciones participan de las mismas opiniones. Un numeroso y variado grupo de autores subraya la obligación de un juez, en una democracia constitucional, de oponerse, por lo menos en casos determinados, a las orientaciones prevalecientes en la comunidad o en las instituciones político-electivas. El papel del juez, en estos regímenes, debe ser entendido como el de un garante o el de un guardián de los derechos fundamentales de los ciudadanos. El moderno constitucionalismo, entendido como técnica de limitación del poder, ha dado prueba de todos estos desarrollos (la reconstrucción de todos ellos puede consultarse en Matteucci 1988).

Es evidente que, en la actualidad, semejante tipo de papel es más fácil que se manifieste sobre todo en aquellos regímenes democráticos que han introducido o reconocido el control jurisdiccional de 
constitucionalidad. En semejantes contextos, el papel del juez puede ser definido como aquel de quien tiene como tarea principal la de defender los derechos de los individuos, de las minorías, de los potenciales abusos de las instituciones político-representativas y de las mayorías que las controlan. El grado de creatividad con el cual semejante papel se ejercita, puede ser definido en sentido restringido si se entiende, por ejemplo, que los jueces deben limitarse a dar reconocimiento a una serie de derechos contenidos en el texto de la Constitución y sólo sobre la base de que esos derechos aparezcan en contraste con otras instituciones políticas. Mas, como puede pensarse, los problemas comienzan a surgir propiamente en este punto. En efecto, definir de manera ejecutiva el control judicial de constitucionalidad parece así menos realista que en el caso del proceso de interpretación de las normas ordinarias. Las normas constitucionales, precisamente por su carácter constitutivo, como por su frecuente y explícita referencia a valores, no parecen ser fácilmente susceptibles de interpretaciones unívocas.

De esta manera, aún en el caso que se reconociese a los jueces un papel político autónomo, el problema de los márgenes de creatividad que ellos dispondrían, asume obviamente un mayor relieve. La discusión sobre este tema ha alcanzado auténticos niveles de sofisticación y de complejidad en los Estados Unidos, posiblemente porque allí, desde hace tiempo, los jueces independientes despliegan un verdadero papel político, relativamente autónomo. Haciendo una simplificación de las numerosas posiciones que han destacado en esa discusión se puede decir que, a partir de quien entiende que el texto constitucional puede dictar a los jueces soluciones unívocas (posición representada por Berger 1977), la mayor parte de los autores reconoce la inevitable presencia de márgenes para la creatividad aún cuando entiende necesario que ella encuentre un límite cuando se expresa exclusivamente en la defensa de determinados derechos o principios. Existe, en primer lugar, la opinión que busca resolver el problema de la legitimación democrática de la jurisdicción justificándola funcionalmente. Así, una tarea de la magistratura -y con ella se formula una referencia concreta a la Corte Suprema de los Estados Unidos- es la de asegurar el buen funcionamiento del proceso de representación política, vigilando con particular atención los procesos electorales (opinión sustentada por Ely 1980 y Choper 1980).

De esta manera, asimismo, tendrían explicación otros fenómenos que se producen en el plano de la cultura de los jueces, los cuales han afectado de manera profunda el papel que los jueces y la jurisdicción comenzaron a asumir en Europa al promediar la década de 1970 y que ya se han manifestado en España en los últimos tiempos. 
5.2. Legitimación de la magistratura ante el cambiante papel de la jurisdicción. Antes se ha dicho que, en el proceso de afirmación del Estado de derecho la legitimación de la intervención del juez provenía de su respeto por la legalidad vigente y de su capacidad profesional para salvaguardar la certeza del derecho. Pero, en la configuración del Estado social dicha legitimación se produce en la medida que sus intervenciones procuran responder las crecientes demandas y reivindicaciones inherentes al vasto tema del bienestar (cfr. Ferrarese 1984:103). Esto provoca no sólo la transformación del papel del juez, sino también un cambio en su percepción cultural de los fenómenos y situaciones sobre los que es llamado a decidir.

No hay que olvidar, asimismo, que la transformación y el refuerzo del papel de la jurisdicción derivan de su colocación estratégica en el sistema político-institucional la cual, de modo casi físiológico, la convierte en la primera instancia que encuentran aquellos nuevos sujetos e intereses sociales que están a la búsqueda de su legitimación. Ello ha sucedido en materia de ambiente; de tutela de los consumidores; de intervención de sujetos colectivos; de problemas relacionados con la difusión de las tecnologías electrónicas, genéticas o de la reproducción. En todas estas situaciones y en otras muchas más son siempre los jueces quienes resultan los primeros destinatarios de las nuevas demandas sociales.

El sistema judicial se convierte así en un instrumento de directa intervención y participación de los ciudadanos. Son los sujetos individuales y los colectivos que ven obstaculizado su acceso a los lugares tradicionales de la representación quienes, a través de la jurisdicción, hacen sentir sus voces y obtener así resultados que de otra forma serían del todo imposibles.

Tal como ha sido descripto el nuevo papel de la jurisdicción en las sociedades avanzadas de Europa continental, una pregunta surge casi espontánea para los defensores de una simple democracia de las formas. ¿Constituye ese nuevo papel de los jueces una distorsión de la forma-Estado prevista por el constitucionalismo social, habida cuenta de la asunción de funciones por parte de sujetos institucionales que, como ellos, carecen de la legitimación democrática atribuida a las instancias ejecutiva y legislativa?

Desde que Edmund Burke escribió su famosa Carta a los electores de Bristol en 1774, la representación política fue considerada la llave maestra del sistema político de la democracia parlamentaria. Sobre esta idea se ha basado el desenvolvimiento posterior de los regímenes democrático-liberales en Occidente. Sin embargo, la evolución de la forma-Estado democrática y de derecho, heredera de aquella tradición, ha atravesado diversas crisis a lo largo del s. XX que le han provocado una pérdida de consistencia. La más profunda 
y reciente de tales crisis es la que ha afectado en las dos últimas décadas al contenido de Welfare con el cual se había completado esa forma-Estado. De este modo, importantes factores sociales han contribuido a la crisis de representación a la que me estoy refiriendo. Algunos de ellos, ya anteriormente aludidos, pueden ser sintetizados en los siguientes aspectos: la pérdida de relevancia del conflicto entre trabajo y capital; la excesiva fragmentación de los intereses sociales; el fenómeno de las agregaciones transitorias; la pérdida de centralidad del circuito Ejecutivo (Gobierno)-Parlamento como itinerario de las decisiones políticas; la reducción de la política económica a política coyuntural y de meras maniobras monetarias (cfr. Fernández Campilongo 1987:97-98).

Lo que parece que en la actualidad puede afirmarse con bastante certeza es que la mayor parte de aspectos que han constituido la crisis de la representación y representatividad política no pueden seguir siendo tratados ya dogmáticamente o según un enfoque normativista. Los fenómenos que han provocado tal crisis no fueron tenidos en cuenta por los teóricos que consideraron a la representación política como el sustento y la savia del sistema democrático-liberal, no sólo porque entonces esos fenómenos no se habían producido, sino también porque en general lo hicieron desde una perspectiva única de las normas establecidas por el ordenamiento jurídico que regula la tradicional representación parlamentaria. Este tipo de abordaje de la representación política presenta sin duda algunas limitaciones y esto ya fue reconocido en España, incluso antes de la transición a la democracia, por Pablo Lucas Verdú (cfr. 1965: 31) quien reconocía entonces que el sistema representativo era un caso típico que corrobora la relativización del derecho constitucional frente a las realidades políticas, a la vez que no creía posible explicar satisfactoriamente, con argumentos apoyados en simples normatividades constitucionales, el profundo cambio que la representación política ha experimentado desde el liberalismo clásico hasta la democracia de masas.

El potencial de representación de un sistema político debe ser analizado y valorado con referencia a todas las organizaciones que se presentan como instancias de representación y que se confrontan, más o menos frecuentemente, más o menos concientemente, más o menos eficazmente, con las demandas de los ciudadanos y las respuestas de los gobernantes (cfr. Pitkin 1985). La importancia de la dimensión formal de la representación no puede desconocerse, pero los esquemas éticos o jurídico-analíticos para analizar el fenómeno en los sistemas políticos contemporáneos no son sólo insuficientes sino que también son impermeables a las contribuciones de las ciencias sociales como un todo y de la sociología política en particular. Por ello, es relevante para el enfoque pluridisciplinar de los fenómenos 
jurídicos -y no cabe duda que la representación también lo es- el examen tanto de las estructuras formales que componen el ordenamiento legal, como los procesos sociales sobre los cuales actúan las reglas de derecho. De tal modo, centrar el enfoque del fenómeno de la representación, por ejemplo, entre las posiciones extremas de Hans Kelsen y Carl Schmitt o sea, dar un puesto de importancia a la falsa contraposición entre mediación y decisión (como dice Rusconi 1984) como parece surgir de algunas de las exposiciones formuladas en el interesante debate sostenido no hace mucho en España, sostenido exclusivamente por filósofos del derecho (cfr. Doxa 1989), supone una simplificación analítica de la representación pues ésta queda reducida a una vinculación orgánica entre la expresión de las exigencias, su recepción por parte de los gobernantes (cuyo mandato es periódicamente verificado y puede ser revocado por medio de las consultas electorales) y la traducción de las preferencias en decisiones (cuyos efectos también ellos pueden incidir sobre la verificación electoral del mandato). En una palabra, en esta perspectiva el consenso electoral es la norma y todo el problema de la representación política queda reducido al análisis de su única dimensión parlamentaria.

La cuestión principal que hoy está planteando la representación política es la de saber cómo y quién reduce la complejidad que abruma las sociedades contemporáneas. No es ésta la sede ni la ocasión para adentrarse en semejante cuestión cuya solución se ha propuesto seriamente desde una perspectiva sistémica. Pero, tomando en cuenta la segmentación de los grupos, la fragmentación de las clases, los contradictorios procesos de redistribución y concentración del poder, en suma la complejidad sociopolítica, ¿quién y de qué modo debe estar autorizado a seleccionar las exigencias y así reducir la complejidad? Por lo que se ha visto, esta pregunta no tiene una única respuesta desde lo que se entiende por representación parlamentaria.

En consecuencia, frente a la crisis de la representación política ha sido la administración de justicia la que ha debido encarar los conflictos que no encontraban respuestas en las sedes institucionales del sistema democrático representativo. Y, es en este punto, entonces, en el que vuelve a entrar en cuestión el problema de la legitimación democrática de los jueces en el marco de las administraciones de justicia de derecho continental, habida cuenta que no se puede tomar como único criterio de dicha legitimación el de la investidura popular. En efecto, esta investidura popular no es la única forma de legitimación democrática, sobre todo cuando, por ejemplo, este tipo de legitimación puede ser deducida de su exposición al control de una institución determinada; para el caso de las democracias sociales, la de los Tribunales Constitucionales. La transparencia institucional que otorga una sentencia judicial constituye seguramente un fuerte 
instrumento de legitimación de la decisión del órgano que la ha tomado. La transparencia institucional, en otros términos, se presenta entonces como un complemento, o un fundamento, de la constitución de la legitimación democrática, o de su permanencia.

La legitimación democrática de los jueces y sus decisiones se acrecienta entonces cuando la sede jurisdiccional se presenta, al menos tendencialmente, como lugar de representación de sujetos e intereses de otro modo excluídos, condenados al silencio. Dar voz a los ciudadanos es, en efecto, una función típica de la democracia (v. Rodotá 1992: $175)$.

Por lo tanto, ante la debilidad de las formas clásicas de la representación liberal, provocada por la crisis que afecta a los sistemas políticos de buena parte de Europa continental, el protagonismo judicial de los últimos años no puede ser visto como una tentativa de «gobierno de los jueces» ni como una «politización de la justicia» sino, antes bien, como un soporte de la democracia representativa y un elemento corrector de los demás poderes constitucionales.

\section{BIBLIOGRAFÍA}

Baratta, A. (1990), «Le fonti del diritto ed il diritto giurisprudenziale», en Materiali per una storia della cultura giuridica, a. XX, n. ${ }^{\circ} 1$-giugno, 189-210.

Bell, J. (1983), Policy Arguments in Judicial Decisions, Clarendon Press, Oxford.

Bergalli, R. (1984), Estado democrático y cuestión judicial, Depalma, Buenos Aires.

Bergalli, R. (1993), «Protagonismo judicial y sistema político (Una espina clavada en el corazón de capitalismo)», en No hay derecho, año IV, n. ${ }^{\circ}$ 10: Buenos Aires.

Berger, R. (1977), Government by Judiciary, Harvard University Press, Cambridge-USA.

Cappelleti, M. (1984), Giudici legislatori, Giuffré, Milano.

Cotterell, R. (1984), The Sociology of Law: an Introduction, Butterworths, London; hay versión en castellano (trad. C. Pérez Ruiz; Introduc. A. Pérez Luño), Ariel, Barcelona, 1990.

Choper, J.-H. (1980), Judicial Review and the National Political Process, The University of Chicago Press, Chicago.

Dahl, R. (1957), «Decision-Making in a Democracy: The Role of the Supreme Court as a National Policy Maker», en Journal of Public Law, VI, 279-295.

Doxa (1989), «Democracia y Representación», vol. 6, 95-215: Alicante.

Dworkin, R. (1977), Taking Rights Seriously, Clarendon, Oxford; hay versión en castellano, Los derechos en serio (trad. M.Guastavino), Ariel, Barcelona, 1984; versión en italiano, I diritti presi sul serio (trad. G. Rebuffa), il Mulino, Bologna, 1982. 
Ely, J.-H. (1980), Democracy and Distrust, Harvard University Press, Cambridge-USA.

Fernández Campilongo, C. (1987), Representaçao Politica e Ordem Jurídica (Os dilemas da democracia liberal), Disertación para obtener el arado de Maestría en el Departamento de Filosofía e Teoría Geral do Direito da Universidade de Sao Paulo; hay una versión abreviada, con el mismo título en, Serie Principios-Editora Atica: Sao Paulo, 1988.

Ferrajoli, L. (1989), Diritto e ragione (Teoria del garantismo penale), Laterza, Roma-Bari, 2. ${ }^{a}$ ed. 1990; versión en castellano, 1995, editorial Trotta, Madrid.

Ferrajoli, L. (1992), «La conquista dell'America e la dottrina della sovranità esterna degli Stati», en

Sessione del Tribunale Permanente del Popoli sul V. Centenario della Conquista dell'America, Padova-Venezia 5 -9. ottobre; hay versión en castellano (trad. R. Bergalli y H. Silveira), en R. Bergalli/ E. Resta (coords.) La soberanía: aspectos metodológicos, jurídicos y políticos, (en curso de publicación), Oñati, Madrid, IISJ-Trotta.

Ferrarese, M. ${ }^{a}$ R. (1984), Le istituzioni difficile. La magistratura trà professione e sistema politico, ESI, Napoli.

Friedman, W. (1961), «Legal Philosophy and Judicial Law», en: Columbia Law Review, LXI, $821-845$.

Habermas, J. (1979), Legitimationsprobleme in Spätkapitalismus, Suhrkamp Verlag, Frankfurt a. M, 5. ${ }^{\mathrm{a}}$ ed.; $1 .^{\mathrm{a}}$ ed. 1973

Luhmann, N. (1971), «Komplexität und Demokratic», en Politische Plannung, Westdeutscher Verlag, Opladen.

Luhmann, N. (1972), Rechtssoziologi, 2. rororo Studium 580-Rowohlt Taschenbuch Verlag: Reinbek bei Hamburg,

Magistratura Democrática (1994), Giudici e democrazia. Magistratura progressista nel mutamento istituzionale, (a cura di N. Rossi) Franco Angeli, Milano.

Matteucci, N. (1980), Organizzazione del potere e libertà, UTET, Torino.

Pitkin, H. (1985), El concepto de representación, Centro de Estudios Constitucionales: Madrid.

Resta, E. (1993), «En torno a la cultura de la legalidad», en Jueces para la Democracia, n. ${ }^{\circ} 19$, Madrid, 11-13.

Rodota, S. (1992), Repertorio di fine secolo, 55 SagittariLaterza, Roma-Bari.

Rusconi, G. E. (1984), «Autorità, decisione, leadership», en Scambio, minaccia, decisiones, il Mulino, Bologna, 93-133.

Souza Santos, B. de (1987), «Law: a Map of Misreading. Toward a Postmodern Conception of Law», en Journal of Law and Society, vol. 14, n. ${ }^{\circ}$ 3, Autumn, Basil Blackwell, Oxford, 279-302.

Souza Santos, B. de (1992), «O Estado e o direito na transiçao pós-moderna: para um novo censo comun jurídico», en R. Bergalli (coord.), Sentido y razón del derecho (Enfoques socio-jurídicos para la sociedad democrática), Colec. Sociedad-Estado, n. ${ }^{\circ}$ 9, Hacer editorial, Barcelona, 3-36. 
Verdú, P. L. (1965), «John Stuart Mill y la democracia representativa», introd. a: J.-S. Mill, Libertad, Gobierno Representativo, Esclavitud Femenina, Tecnos, Madrid.

Wolfe, C. (1991), Judicial Activism, Pacific Grove, Brooks/Cole.

Zagrebelsky, G. (1992), Il diritto mite (Legge diritti giustizia), Einaudi Contemporanea 14, Giulio Einaudi editore, Torino. 
